\section{Brush between to achieve the best clean}

Getting rid of the bacteria between the teeth is just as important as eliminating the bacteria removed by brushing, but how do your patients reach those tricky spaces?

Revolutionise their oral care routine by recommending Wisdom Clean Between Interdental Brushes. The UK's No.1 selling rubber interdental brushes, these easy-to-use hygiene aids provide a deep clean in places where normal brushes can't reach, eliminating the bacteria between the teeth to help keep patients' mouths healthy.
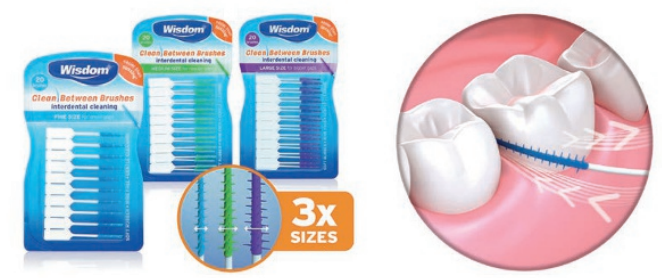

Featuring tiny rubber filaments that gently remove plaque, the brushes are kind to the gums and have been clinically proven to prevent gum disease.

Perfect for everyday use as well as for cleaning around orthodontic appliances, metal fillings, implants, bridges and crowns, these brushes are also latex and wire free. This makes them the ideal choice for people who have had problems with wire interdental brushes, allowing everyone to experience the benefits of a deep clean, in between.

To find out more, please visit www.wisdom-toothbrushes.com or call 01440714800 .

\section{New partnership for clear aligner systems}

Carestream Dental has announced a partnership with ArchformByte - the company behind C-Thru Clear Aligners.

Dentists using the CS 3600 or CS 3500 intraoral scanners from Carestream Dental are now able to send the accurate images captured to ArchformByte instantly online for fast and efficient production of C-Thru aligners within one working day. This will ensure dentists can provide the highest standard of service to all patients suitable for treatment with the various C-Thru clear aligner systems.

Pennie Hudson-Ward, CEO of Archformbyte, said: 'We are delighted to have the opportunity to work with Carestream Dental. The CS 3500 and CS 3600 intraoral scanners are incredibly compatible with our C-Thru Clear Aligners, and produce great results for both patients and dentists. In order to help dental practices see an increased profit straight away, we are offering any practice that purchases a Carestream Dental intraoral scanner through Archformbyte a free C-Thru case, which is worth up to $£ 1350$, and a $10 \%$ discount on all future cases.'

For more information please contact Carestream Dental on 08001699692 or visit www.carestreamdental.co.uk.

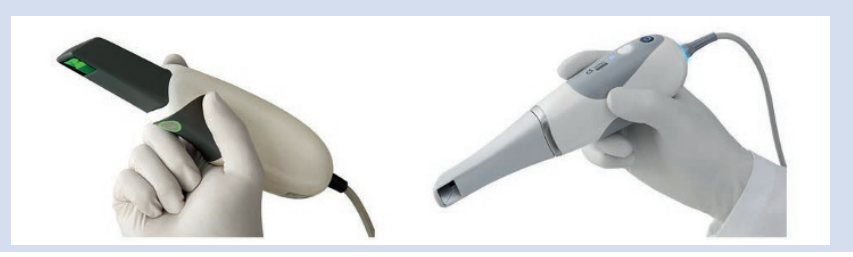

\section{Cutting-edge innovation}

Using the latest technology and innovative techniques, Stern Weber offers clinicians the very best in dental unit design. Rigour and precision are the key aspects of each Stern Weber creation, helping dentists to work efficiently, effectively and flexibly.

There are three series:

- The $\mathrm{S}$ series, a range of dental units where the patient chair and the unit body are attached to each other for complete synchronism

- The TR series, which has a freestanding unit body independent from the patient chair and its movements for optimal ergonomics, stability and use of space

- The TRC series, which thanks to the suspended patient chair helps to creatively maximise the space available.

Stern Weber also offers an extensive range of instruments and accessories so that you can assemble a dental unit that is suited to your specific clinical needs and preferences.

To find out more contact RPA Dental Equipment Ltd at www.rpadental.net or call 08000933975.

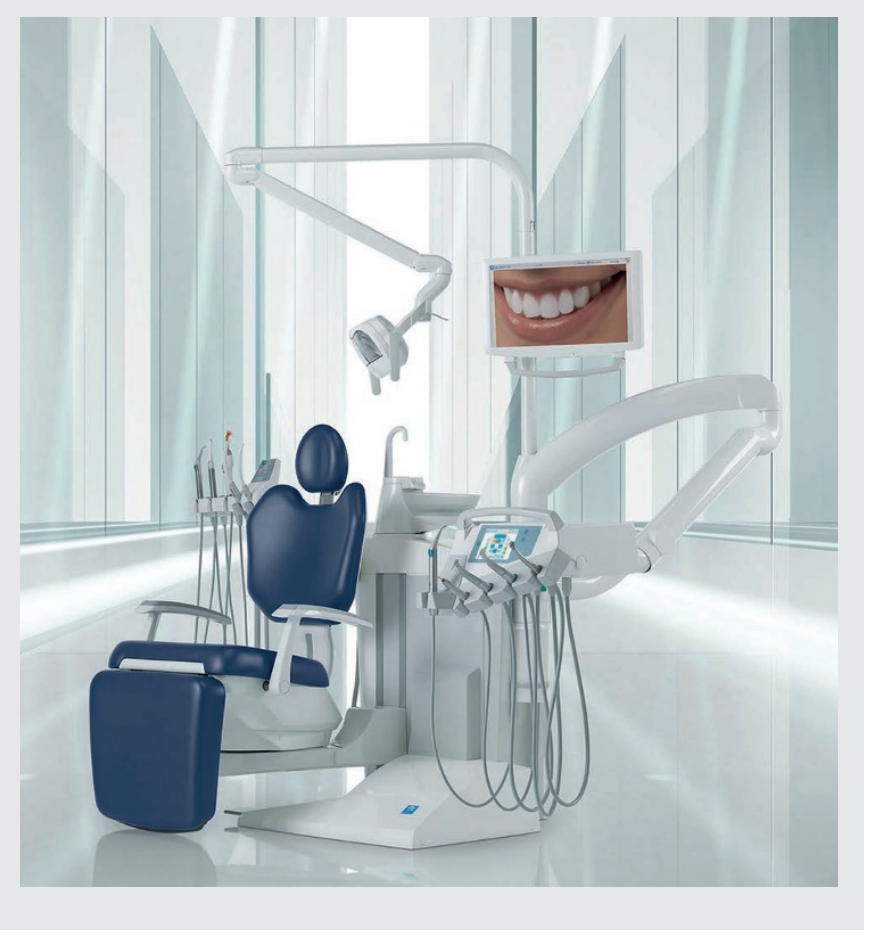

\section{Putting patient comfort first}

Some impression materials can leave a nasty taste in the mouth - so why not choose a material that puts patient comfort first?

Impregum Super Quick polyether impression material from 3M Oral Care has been developed for a pleasant patient experience. Not only does the material have a working time of just 45 seconds, but it can also set in as little as two minutes - meaning it will be in the patient's mouth for less time and will reduce any discomfort.

The formula also has a fresh, minty flavour, helping patients relax and enjoy the experience without suffering from an unpleasant taste.

For more information, call 0845626578 or visit www.3M.co.uk/ Dental.

$3 \mathrm{M}$ and Impregum are trademarks of the $3 \mathrm{M}$ Company. 